\title{
Listening to the Suicidal in the Wake of Covid-19
}

Vanda Scott

Ms. Vanda Scott is currently the international advisor to the International Association for Suicide Prevention and holds several advisory positions with NGOs including the De Leo Fund. She participated in the development of a worldwide network of agencies for suicide prevention, which enhances cooperation between mental health professionals and volunteers. Her speech will be about cooperative approaches to prevention of suicide with examples on three levels - local, national and international.

Abstract. Unknown, unexpected, medical emergency - Covid-19 a global crisis. In December 2019 coronavirus was identified in China and by early March extended exponentially across many nations, East and West, and the World Health Organisation declared Covid-19, a global pandemic. Globally, governments immediately enforced a range of actions from the research of the virus through to extensive medical treatment, social isolation, workplace and countrywide closures. The impact is unmeasurable and will affect economic and social stability as well as the general and mental health of the population in all countries. Almost $80 \%$ of all suicides occur in the low and middle income countries; these very same countries that will experience even greater inequities during this pandemic due to weak public health systems, lack of mental health professionals and facilities, the negative economic effect of lockdowns and the evident increase in poverty. Along with mental health professionals worldwide, Suicide Prevention Crisis Centres have been in the front line of responding to the public and, unquestionably, will continue to have a significant role in being accessible for those suffering suicidal ideation and behaviour. The purpose of this presentation is to take a small sample of the work from crisis centres in both the developed and developing countries and review the changes in their services that is currently being experienced and also reflect on what could be expected. It is too early to predict the changes in suicidal behaviour. However, this sector is only too aware that there is a need to prepare for an undetermined change in trends in suicidal behaviour along with unknown knowledge on how such changes may be resourced. A few challenging options will be explored. 